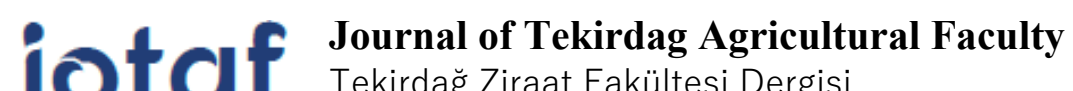 \\ Tekirdağ Ziraat Fakültesi Dergisi
}

\section{Farklı Enterpolasyon Yöntemleri Kullanılarak Toprakların Nem Sabitelerine Ait Konumsal Dağılımların Belirlenmesi, Isparta Atabey Ovası Örneği}

\author{
Determination of Spatial Distribution of Soil Moisture Constant Using Different Interpolation \\ Model Case study, Isparta Atabey Plain
}

\section{Özet}

\section{Pelin ALABOZ ${ }^{*}$, Sinan DEMIIR ${ }^{2}$, Orhan DENGIZ ${ }^{3}$}

Enterplosyon teknikleri toprak biliminde son yıllarda yaygın olarak kullanılan tekniklerden biridir. Özellikle, yoğun iş gücü ve emek gerektiren analiz sonuçlarının konumsal dağılımlarını belirlemek amacıyla ters mesafe komşuluk benzerliği (IDW), radyal tabanlı fonksiyonlar (RBF) ve Kriging teknikleri yaygın olarak kullanılmaktadır. Bu çalışma, Isparta ili Atabey ovası içerisinde 256 ha alan kaplayan yoğun tarım yapılan arazilerde gerçekleştirilmiştir. $200 \mathrm{~m}$ aralıklarla grid yöntemi ile toplam 113 adet yüzey $(0-20 \mathrm{~cm})$ toprak örneklemesi yapılmış ve alınan örneklerin temel fiziko-kimyasal özellikleri belirlenmiştir. Toprakların su içeriklerine (Tarla kapasitesi-TK, Solma noktası-SN, Yarayışlı su içeriği-YSİ) yönelik uzaysal dağıllım haritalarının belirlenmesi için deterministik ve stokastik (Ordinary Kriging -Küresel, Üssel, Gaussian ve Cokriging) modeller değerlendirilmiştir. Validasyon ve en uygun model seçimlerinde, ortalama mutlak hata (MAE) ve hata kareler ortalaması (RMSE) kullanılmıştır. Çalışma alanı içerisindeki toprakların tekstür sınıfı kil, killi tın, kumlu killi tın, siltli kil, siltli killi tın olarak belirlenmiştir. Toprak organik madde içeriği genellikle düşük, kireç içeriği ise yüksek seviyelerde bulunmuştur. Hafif alkalin reaksiyonlu topraklarda, tuzluluk sorunu görülmemektedir. Tarla kapasitesi, SN ve YSİ sırasıyla \% 23.30-47.57, 12.09-29.50, 9.98-21.87 arasında değişmektedir. Araştırma sonuçlara göre, toprakların tarla kapasitelerine ait uzaysal dağılımlarının elde edilmesinde en uygun model Ordinary Kriging'in Gaussan (RMSE: \% 4.289; MAE: \% 3.267) olarak belirlenirken, solma noktası değerlerinin uzaysal dağılımında stokastik yaklaşım olan Cokriging en uygun dağılımı (RMSE: \% 3.187 ; MAE: \% 2.450) göstermiştir. Toprakların yarayışlı su içeriklerinde ise en düşük RMSE (\%1.421) ve MAE (\% 1.115) ile IDW-1 en uygun model olarak belirlenmiştir. Çalışma sonucunda farklı toprak özelliklerine göre enterpolasyon yöntemlerininin tahmin gücünde farkl11ıkların olduğu bulunmuştur.

\section{Anahtar Kelimeler: Tarla kapasitesi, Solma noktası, Yarayışlı su, Enterpolasyon, Uzaysal dağılım}

\begin{abstract}
In recent years, interpolation techniques have become a commonly used method in soil science. Inverse distance weighting (IDW), radial basis function (RBF), and Kriging techniques are widely used to determining the spatial distribution of particularly labor and effort-intensive analysis results. This present study was carried out in 256 ha of Atabey Plain where has been intensively used as agricultural activity. A total of 113 soil samples $(0-20 \mathrm{~cm})$ were collected on a $200 \mathrm{~m}$-spaced grid, and it was determined for basic Physico-chemical properties in all soil

\footnotetext{
1*Sorumlu Yazar/Corresponding Author: Pelin ALABOZ, Isparta Uygulamalı Bilimler Üniversitesi Ziraat Fakültesi Toprak Bilimi ve Bitki Besleme Bölümü, Isparta ve Türkiye. E-mail: pelinalaboz@isparta.edu.tr (D) OrcID: 0000-0001-7345-938X

2 Sinan DEMIR, Isparta Uygulamalı Bilimler Üniversitesi, Ziraat Fakültesi, Toprak Bilimi ve Bitki Besleme Bölümü, Isparta ve Türkiye. E-mail: demirsinan.07@gmail.com (DD OrcID: 0000-0002-1119-1186.

${ }^{3}$ Orhan DENGIZ, Ondokuz Mayıs Üniversitesi, Ziraat Fakültesi, Toprak Bilimi ve Bitki Beseleme Bölümü, Samsun ve Türkiye. E-mail: odengiz@omu.edu.tr (iD) OrcID: 0000-0002-0458-6016.

Atıf/Citation: Alaboz, P., Demir, S., Dengiz, O. (2020). Farklı Enterpolasyon Yöntemleri Kullanılarak Toprakların Nem Sabitelerine Ait Konumsal Dağılımların Belirlenmesi, Isparta Atabey Ovası Örneği. Tekirdă̆ Ziraat Fakültesi Dergisi, 17 (3), 432-444.

CBu çalışma Tekirdağ Namık Kemal Üniversitesi tarafından Creative Commons Lisansı (https://creativecommons.org/licenses/by-nc/4.0/) kapsamında yayınlanmıştır. Tekirdağ 2020
} 
samples. In order to determine the spatial distribution of soil moisture constant (Field capacity-FC, Wilting pointWP, and Available water capacity-AWC), deterministic and scholastic (Ordinary kriging-Spherical, Exponential, Gaussian and Cokriging) models were used. In addition, mean absolute error (MAE) and root-mean-square error (RMSE) were used to select and validate the best methods. Texture class of soils was determined as clay, clay loam, sandy clay loam, silty clay, silty clay loam in the study area. Soil organic matter content was generally found at low levels and lime content was at high levels. Soils have a slightly alkaline reaction and salinity problem is not observed. Field capacity, WP and AWC varied between 23.30-47.57, 12.09-29.50, 9.98-21.87 \%, respectively. According to obtained results, it was found the Gaussian model of OK (RMSE: \% 4.289; MAE: \% 3.267) for FC as the best model while the most suitable model was Cokriging (RMSE: 3.187\%; MAE: 2.450\%) for WP. The lowest RMSE (1.421\%) and MAE (1.115\%) values were determined in IDW-1 for the available water contents of soils. As a result of the study, it was found that there are differences in the predictive accuracy of interpolation methods according to different soil properties.

Keywords: Field capacity, Wilting point, Available water, Interpolation, Spatial distribution 


\section{Giriş}

Sanayileşen ülkeler tarafından yoğun olarak atmosfere salınan sera gazlarının neden olduğu küresel ısınma; yağış ve sıcaklıklardaki farklılıklar ile iklim değişikliklerine, su kaynaklarının azalmasıyla kuraklığa neden olmaktadır. Küresel ssınmaya bağlı olarak, 2013-2040 yılı periyodunda ilkbahar ve yaz mevsimlerinde sıcaklığın $3{ }^{\circ} \mathrm{C}$ artacağı, ayrıca sonbahar yağışlarında azalışların olacağı belirtilmektedir (IPCC, 2014). Gelecekte beklenilen kuraklık senaryolarına göre, tarımın en temel ihtiyacı olan suyun önemi gün geçtikçe daha da artacaktır. Ülkemizin y1llık ortalama 112 milyar $\mathrm{m}^{3}$ 'lük kullanılabilir su potansiyelinin \%16'sını içme ve kullanmada, \%12'si, sanayide \%72'si ise tarım sektöründe değerlendirilmektedir (DSİ, 2019). Kullanılabilir su potansiyelinin çoğunluğunun tarım sektöründe olduğu göz önüne alındığında toprak neminde ortaya çıkacak azalış; tarımsal üretkenliği olumsuz etkileyerek gelecekte insanların besin gereksinimlerinin karşılanmasında büyük zorluklara yol açacaktır. Bitki yetiştirme ortamında optimum verim için toprakların yarayışlı su ihtiyaçlarının bilinmesi ve bu su düzeyine göre sulamaların yapılması kısıntılı olan suyun ideal kullanımı için oldukça önemlidir (Grewal ve ark., 1990). Bitkilerin sulama zamanı ve verilecek su miktarının belirlenmesinde nem sabitelerinin (tarla kapasitesi, solma noktası) bilinmesi oldukça önemlidir (Mbah, 2012). Sulama programlamalarında verilen suyun ne kadarının toprağın kaç cm'sini ıslatacağı ya da ne kadarının kök bölgesinden uzaklaşacağını değerlendirebilmek için tarla kapasitesi, solma noktası seviyesinde tutulan toprak nem miktarının bilinmesi gerekmektedir. Tarla kapasitesi ve solma noktası arasındaki nem aralığı olan yarayışıı su içeriği de mevcut olan suyu saklama ve serbest bırakma kapasitesini gösteren (Silva ve ark., 2014), toprakların fiziksel özellikleri ve kalitesinin değerlendirilmesinde kullanılan bir parametredir (Hong ve ark., 2013). Genellikle toprak örneklemesine özgü elde edilen nem sabiteleri noktasal bazlıdır. Bazı noktalardan alınan toprak örnekleri araziyi tam anlamıyla temsil etmemekte söz konusu özelliğin alansal bazlı dağılımının belirlenmesi ile daha etkili sonuçlar ortaya çıkmaktır.

Toprak özellikleri farklı mekânsal ve zamansal ölçeklerde çeşitli faktörler tarafından kontrol edilmektedir. Toprakların fiziksel, kimyasal ve biyolojik özellikleri çok kısa mesafelerde değişkenlik gösterebilir (Yıldız, 2011; Aşkın ve ark., 2016). Araziler heterojen bir yapıya sahip ve incelenen özellikler arasında varyasyon yüksek seviyelerde olduğundan kısa mesafelerdeki bu değişkenlik üretim potansiyeli için önemlidir. Çalışılan bir alanda yoğun toprak örneklemesi uygulanabilir ve ekonomik bir yaklaşım değildir. Tarımsal alanlarda toprak özelliklerinin mekânsal ve zamansal değişkenliğini anlamak doğal kaynakların sürdürülebilir kullanımı açısından önemlidir (Sağlam ve ark., 2014). Bu kapsamda toprakların mekânsal değişkenliklerinin saptanabilmesi adına jeoistatistiksel metotlar son dönemde yaygın olarak kullanılmaktadır. Bölgede oluşturulan dağılım haritalarında farklı enterpolasyon teknikleriyle mekânsal değişiklikler belirlenebilmektedir. (Özyazıcı ve ark., 2016; Tunçay ve ark., 2018; Dengiz ve ark., 2019; Aydın ve Dengiz, 2019; Arslan 2012; Arslan 2014; Bayat ve ark., 2013; Celilov ve Dengiz, 2019). Noktasal verilerin alansal dağılımını belirlemek için deterministik ve stokastik olarak 2 farklı enterpolasyon tekniği bulunmaktadır. Deterministik yöntemlerden; ters mesafe komşuluk benzerliği (IDW) ya da farklı özelliklerde bağlayıcı eğri oluşturma (spline) radyal tabanlı fonksiyonlar (RBF), jeoistatistik yöntemlerden (stokastik) ise doğal kriging (OK), basit kriging (SK), evrensel kriging, cokriging (CoK) ve indikatör kriging (IK) kullanılan yöntemler arasındadır. Tarla kapasitesi, solma noktası ve yarayışı su gibi nem sabitelerinin mekânsal değişiminin izlenmesi özellikle su kısıtı gözlenen kurak ve yarı kurak alanlarda verimliliğin arttırılabilmesi adına önemli bir yaklaşımdır.

Yoğun tarımsal üretimin gerçekleştiği Isparta ilinde tarımsal üretimin yapıldığı önemli ovalarından biri Atabey Ovasıdır. Ürün veriminde oldukça önemli olan suyun etkin kullanımı adına bölgede tarla kapasitesi, solma noktası ve yarayışlı su içeriğinin mekânsal dağılım olarak belirlenmesi ve buna uygun sulama programlarının planlanması kısıntılı olan su kullanımında optimum verime katkı sağlayacaktır. Bu çalışmada; i-) Ovada dağılım gösteren toprakların tarla kapasitesi, solma noktası ve yarayışı su içeriklerinin değerlendirilmesi, ii-) söz konusu nem sabitelerinin farklı enterpolasyon modelleri ile değerlendirilmesi ve dağılım haritalarında en güvenilir enterpolasyon yönteminin belirlenmesi amaçlanmıştır. 


\section{Materyal ve Metot}

\section{1. Çalışma alanı}

$\mathrm{Bu}$ çalışma, Isparta ilinin Atabey ilçesinde yürütülmüştür. Çalışma alanı Batı Akdeniz bölgesi sınırları içerisinde Isparta il merkezinin 15 km doğusunda bulunmakta olup 4197100-4198600N kuzey enlemleri -294200295700E doğu boylamları (WGS-84, UTM-m, 36 Zon) arasında yer almaktadır. Çalışma alanı 256 ha olup, deniz seviyesinden yükseklik 884 m ile 974 m arasında yer almaktadır. Alan, Atabey Ovası içerisinde düz düze yakın (\%0-2) eğimlidir. Eğim kuzeye doğru ilerledikçe artış göstermektedir (Şekil 1).

Atabey ilçesi yaklaşık 8558 ha (\%38.45) tarımsal alana sahiptir. Tarım arazilerin \% 5.84’ünü kuru tarım, \% 14.81'ini sulu tarım, \% 8.72' sini sulanmayan karışık tarım, \% 7.11'ini sürekli sulanan karışık tarım, \% 0.81'ini mera alanları ve \%1.16'lık kısmını diğer alanlar oluşturmaktadır (Corine, 2018). Bölge kolüvyal büyük toprak grubu içerisinde olup düz ve düze yakın eğimli, I. sınıf arazi yetenek sınıfında yer almaktadır. Bölge jeolojisini holosen yaşı birikintiler oluşturmaktadır. Atabey Ovası doğusu, kuzeyi ve güneyi yüksek dağlarla çevrili dışarıya açılan akıntısı olmayan çanak görünümündedir. Jeolojik süreç içerisinde Mesozoil Tersiyer kireçtaşları, taşınmanın etkisiyle çanak biçiminde olan ovanın eteklerinde ve ortasında birikimler oluşturmaktadır. (Akgül ve ark., 2001).

Çalışma alanının uzun yıllar (1960-2018) meteorolojik verilerine göre (MGM, 2018), bölgedeki yarı kurak iklim tipi hakimdir. Yıllık ortalama sıcaklık, yağış ve evapotranspirasyon sırasıyla $12.5^{\circ} \mathrm{C}, 466.8 \mathrm{~mm}$ ve 724.58 mm'dir. Toprak iklim rejimi için Newhall simülasyon modeline göre, çalışma alanının toprak sıcaklığı ve nem rejimleri sırasıyla mesic ve xeric (alt grupta kuru xeric) 'dir (Van Wambeke, 2000).

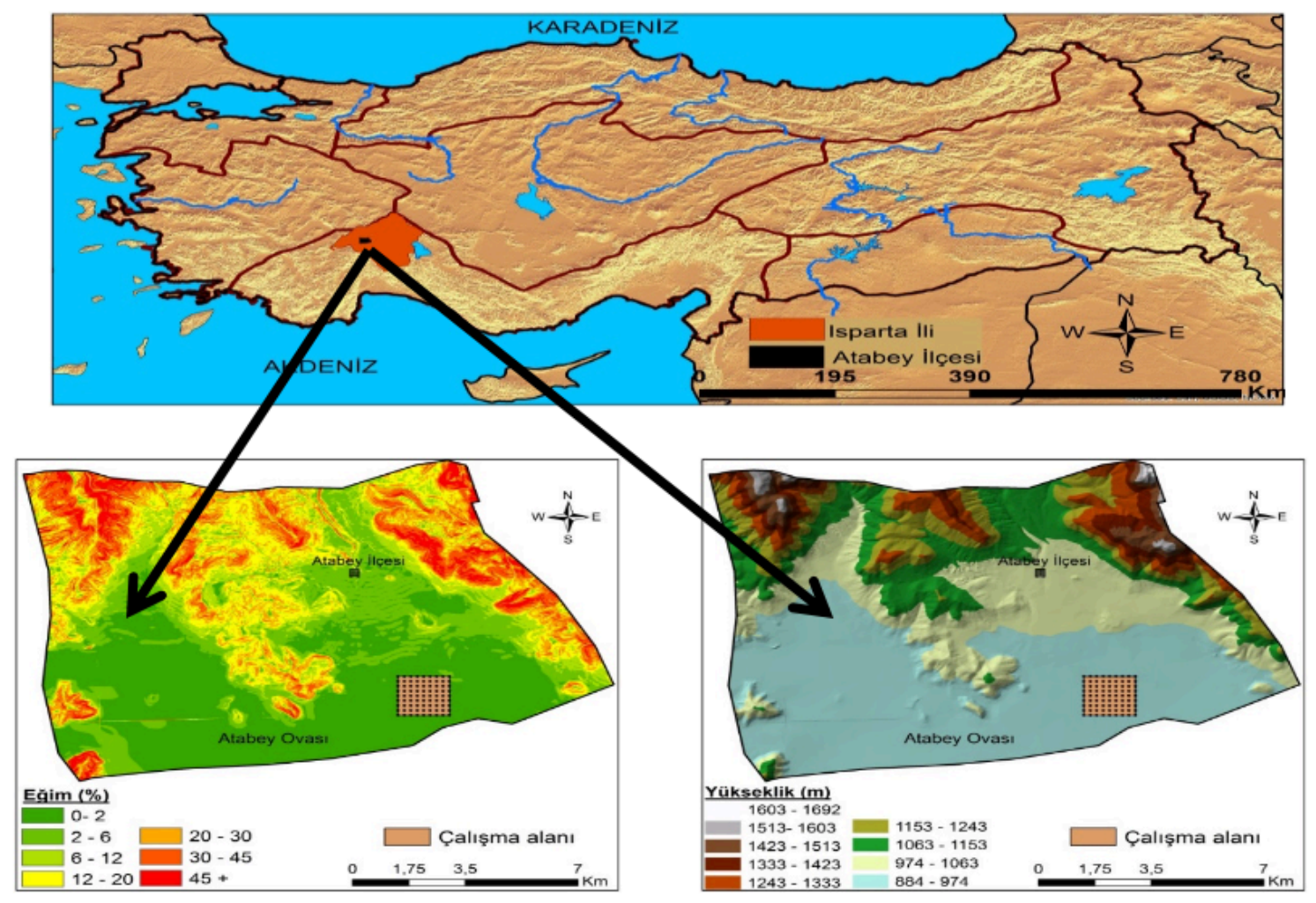

Figure 1. Location, height and slope maps of the study area

Şekil 1. Çalışma alanı lokasyon, yükseklik ve ĕğim haritaları 


\subsection{Yöntem}

\subsubsection{Toprak örnekleme ve analizler}

Atabey Ovası içerisindeki çalışma alanında, $200 \mathrm{~m}$ mesafeli grid sistemi oluşturulmuş ve oluşturulan grid yöntemine göre 113 noktadan bozulmuş ve bozulmamış yüzey örneklemesi $(0-20 \mathrm{~cm})$ yapılmıştır. Örnekleme noktalarının \%70'i grid yöntemine göre \% 30’u ise validasyon için grid noktaları arasından (100m) seçilmiştir. Laboratuvara getirilen örnekler, köklerden ve kaba parçacıklardan ayrıldıktan sonra fiziksel ve kimyasal analiz için hazır hale getirilmiştir.

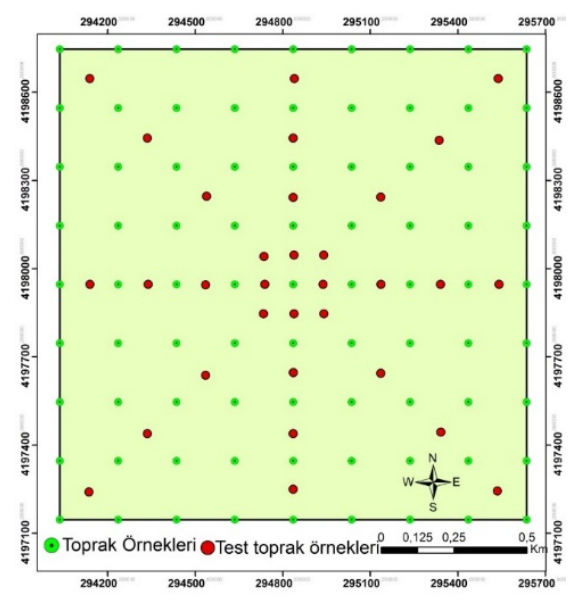

Figure 2. Soil sampling pattern

\section{Şekil 2. Toprak örnekleme deseni}

Toprakların tekstürü (\% kum, silt, kil) Bouyoucos hidrometre yöntemiyle (Bouyoucos, 1962), hacim ağırlığ1 $100 \mathrm{~cm}^{3}$ hacmine sahip bozulmamış örnek alma silindirleri yardımıyla belirlenmiştir (Burt, 2014). 1:1 toprak-su süspansiyonunda toprakların elektriksel iletkenlik (EC) ve pH'ları belirlenmiştir (U.S.Salinity Laboratory Staff, 1954; Kacar, 2009). Volumetrik kalsimetre yöntemiyle eşdeğer kireç ( $\left.\mathrm{CaCO}_{3}\right)$ içeriği (Soil Survey Staff, 1992), değiştirilmiş Walkley-Black yöntemiyle ise toprakların organik madde (OM) içerikleri hesaplanmıştır (Kacar, 2009). Tarla kapasitesi (TK) ve solma noktası (SN) için 0.33 bar ve 15 bar tansiyonlarda tutulan su, seramik tablalı pF seti (U.S.A, Soil Moisture Equipment Corp.) yardımıyla hacimsel olarak belirlenmiştir. Yarayışlı su içerikleri (YSI) tarla kapasitesi ve solma noktası arasındaki fark alınarak bulunmuştur (Burt, 2014).

\subsubsection{Enterpolasyon yöntemleri}

İncelenen toprak özelliklerinin temel tanımlayıcı istatistikleri (minimum, maksimum, çarpıklık, basıklık vb), Minitab 16 paket programında belirlenmiştir. Toprak özelliklerinin dağılımları Kolmogorov-Smirnov testi ile kontrol edilmiştir. Bu çalışmada, TK, SN ve YSİnin mekansal dağılımını tahmin etmek için farklı enterpolasyon yöntemleri [Ters mesafe komşuluk benzerliği (IDW), radyal tabanlı fonksiyonlar (RBF), ordinary kriging (OK) ve cokriging $(\mathrm{CoK})]$ uygulanmıştır.

Çalışmada, jeoistatistiksel çalışmalarda en yaygın kullanılan OK ve CoK (Cemek ve ark. 2007; Zhou ve ark. 2012) yöntemi seçilmiş, jeoistatistiksel tahminden önce, örnek çiftleri arasındaki mesafe sınıfları için bir variogram hesaplanmıştır. Ordinary kriging metotlarında Küresel (Spherical), Üssel (Exponential) ve Gaussian modeller kullanılmıştır. Cokriging yönteminde, uzamsal dağılımlar oluşturmak için küresel bir variogram modeli kullanılmıştır. Tahminler aşağıdaki formül kullanılarak belirlenmiştir (Eş. 1).

$$
Z=\sum_{i=1}^{n} W i . Z(X i) \quad \text { (Eş. 1) }
$$

Z: tahmin değeri, Z(Xi): Xi'de ölçülen değer, Wi: Z (Xi) verilerine atanan ağırlıktır, n: alanda kullanılan örnek sayıs1. 
Çalışma alanında TK, SN ve YSİ değerlerinin kil içeriğini yardımcı değişken olarak kullanarak alansal dağılım haritasını oluşturmak ve nokta kestirimi yapmak amacıyla CoK aşağıdaki formül ile hesaplanmıştır (Eş.2).

$$
Z=\sum_{i=1}^{n} W i . Z i+\sum_{j=1}^{m} W j . Y i
$$

$\mathrm{Z}$ : tahmin değeri, Wi Wj, sırasıyla $\mathrm{Z}$ ve $\mathrm{Y}$ değişkenlerine ait ağırlıkları, $\mathrm{m}$ ve n'ler ise sırası ile $\mathrm{Z}$ ve $\mathrm{Y}$ değişkenlerine ait kestirimde kullanılan veri sayısını ifade eder.

Ters mesafe komşuluk benzerliği yöntemi, örneklenmiş noktalardaki değerlerin doğrusal kombinasyonunu kullanarak örneklenmemiş noktalardaki değerleri, uzaklıkların ters mesafe fonksiyonlarından yararlanarak tahminler oluşturmaktadır. Ters mesafe komşuluk benzerliği enterpolasyonu, coğrafi bilgi sistemlerinde nokta verilerinden raster katmanları oluşturmak için kullanılır. Veriler düzenli bir grid sisteminde olduğunda, kontur çizgileri enterpolasyonlu değerlerden geçirilebilir ve harita bir vektör kontur haritası veya raster gölgeli bir harita olarak oluşturulabilir (Burrough ve Mcdonnell 1998). Tahminler aşağıdaki formül kullanılarak belirlenmiştir (Eş. 3).

$$
Z=\left[\sum_{i=1}^{n}\left(Z i / d i^{m}\right) / \sum_{i=1}^{n}\left(1 / d i^{m}\right)\right]
$$

Z: tahmin edilen değer, Zi: bilinen noktadaki değer, di: i noktası ile değeri tahmin edilecek noktadaki mesafe, m: ağırlık kuvveti (genellikle 1-5 arasında kullanılır). Bu çalışmada IDW'nin tahmininde yaygın olarak kullanılan ağırlık kuvvetleri (1, 2 ve 3. kuvvet) kullanılmıştır (Pirmoradian ve ark.2010; Keshavarzı ve Sarmadian 2012).

Radyal tabanlı fonksiyonlar yönteminde, enterpole edilmiş yüzeyin, ölçülen her numune değerinden geçmesi gereken bir dizi kesin enterpolasyon tekniği kullanılmaktadır. Çok boyutlu verilerin enterpolasyonunda kullanılan bir yöntemdir. İnce plaka spline (Thin-plate spline-TPS), gergin spline (Spline with tension-SPT), tamamen düzenli spline (Completely regularized spline-CRS), çoklu kuadrik fonksiyon (MQ) ve ters kuadrik fonksiyon (IMQ) olmak üzere beş farklı temel fonksiyon ile tahminlemeler yapılabilmektedir (Xie ve ark.2011). En yaygın kullanılan CRS, TPS ve SPT radyal fonksiyon enterpolasyonları, tarla kapasitesi, solma noktası ve yarayışlı su içeriği dağılımını değerlendirmek için seçilmiştir.

\subsubsection{Enterpolasyon yöntemlerinin karşılaștırılması}

Modellerin tahmin gücünün değerlendirilmesinde çapraz validasyon ve validasyon, yöntemleri tercih edilmektedir. Bu çalışmada, interpolasyon yöntemlerinin değerlendirmek için bağımsız bir veri seti kullanılmıştır. Birçok araştırmacı, en iyi örnekleme tekniklerini belirlemek için farklı eğitim ve test setleri kullanmaktadır. Farklı oranlarda olmak üzere tahmin modellerinde bir eğitim birde modeli doğrulama setleri kullanılmaktadır (Tutmez ve Hatipoğlu 2010; Falamaki 2011; Ahmadi ve Dezfouli 2011). Bu çalışmada, 113 örnekleme noktası rastgele iki gruba ayrılmıştır. Örnekleme noktalarının \%70'i modelleri geliştirmek için, \% 30'u ise bağımsız bir doğrulama işlemi için kullanılmıştır. Farklı enterpolasyon teknikleri ile gözlenen ve tahmin edilen değerler arasındaki ilişkileri değerlendirmek için hata karelar ortalaması karekökü (RMSE), mutlak ortalama hata (MAE) ve belirleme katsayısı $\left(\mathrm{R}^{2}\right)$ parametreleri kullanılmıştır. Yüksek $\mathrm{R}^{2}$ ve düşük RMSE ve MAE en doğru tahminleri göstermektedir. Tahminler aşağıdaki formüller kullanılarak belirlenmiştir (Eş. 4, 5, 6).
$M A E=\frac{1}{n} \sum_{i=1}^{n}|Z i-Z|$
$\operatorname{RMSE}=\sqrt{\frac{\sum(\mathrm{Zi}-\mathrm{Z})^{2}}{\mathrm{n}}}$
$\mathrm{R}^{2}=\left[\frac{\sum Z i Z-\frac{\sum Z i \sum Z}{\mathrm{n}}}{\sqrt{\left[\sum Z i^{2}-\frac{\left(\sum Z \mathrm{i}\right)^{2}}{\mathrm{n}}\right]\left[\sum Z^{2}-\frac{\left(\sum Z\right)^{2}}{\mathrm{n}}\right]}}\right]^{2}$
Zi: tahmin değeri, Z: gerçek değer, n: gözlem sayısı 


\section{Araştırma Sonuçları ve Tartışma}

\subsection{Toprakların genel özellikleri}

Toprakların temel fiziko-kimyasal özelliklerine ait tanımsal istatistik değerleri Tablo 1'de belirtilmiştir. Çalışma alanı topraklarının kum, silt ve kil içerikleri sırasıyla \%10.08-64.61, \%16.35-60.18, \%17.16-57.70 arasında değişmektedir. Orta-ince bünye grubunda alan toprakların tekstür sınıfları C, CL, SCL, SiC, SiCL olarak belirlenmiş̧ir. Akgül ve ark., (2002) Ova toprakları için yaptıkları toprak etüd ve haritalama çalışmasında toprakların \%81'ini orta-ince, \%19'unu kaba tekstürlü alarak belirlemişlerdir. Toprakların varyasyon katsayılarında değiş̧kenlik en yüksek organik madde, en düşük ise pH'da belirlenmiştir.

\section{Tablo 1. Toprak özelliklerinin tanımlayıct istatistikleri}

Table 1. Descriptive statistics of soil properties

\begin{tabular}{llllll}
\hline & Min. & Max. & VK(\%) & Çarpıklık & Basıklı \\
\hline Kum (\%) & 10.08 & 64.61 & 39.96 & 0.76 & 0.16 \\
Silt (\%) & 16.35 & 60.18 & 22.72 & 0.47 & 0.86 \\
Kil (\%) & 17.16 & 57.70 & 30.85 & 0.21 & -1.18 \\
pH & 7.85 & 8.39 & 1.33 & -0.34 & 0.35 \\
EC $\left(\mathrm{dS} \mathrm{m}^{-1}\right)$ & 0.13 & 0.37 & 24.15 & 0.64 & -0.12 \\
$\mathrm{OM}(\%)_{\mathrm{CaCO}}(\%)$ & 0.38 & 3.87 & 55.07 & 0.90 & 0.94 \\
$\mathrm{HA}\left(\mathrm{g} \mathrm{cm}^{-3}\right)$ & 1.07 & 34.27 & 17.76 & 0.33 & 0.06 \\
$\mathrm{TK}(\%)$ & 23.30 & 47.57 & 11.30 & 0.22 & -0.28 \\
$\mathrm{SN}(\%)$ & 12.09 & 29.50 & 14.66 & 0.16 & 0.78 \\
YSI $(\%)$ & 9.98 & 21.87 & 13.68 & 0.83 & 0.27 \\
\hline
\end{tabular}

EC: Elektriksel iletkenli, OM: Organik madde, $\mathrm{CaCO}_{3}$ :Eşdeğer kalsiyum karbonat içeriği, Ha: Hacim ağırlı̆̆ı, TK: Tarla kapasitesi, SN: Solma noktası, YSi: Yarayışlı su içeriği, Örnek sayısı (n):113

Toprakların pH'ları 7.85-8.39, EC içerikleri ise 0.13-0.37 $\mathrm{dS} \mathrm{m}^{-1}$ arasında değişmektedir. Genellikle hafif alkalin reaksiyonlu topraklarda, tuzluluk sorunu görülmemektedir. Toprakların kireç içerikleri \% 14.77-34.27, organik madde ise \% 0.38-3.87 arasında değişim sergilemiştir. Doran ve Jones, (1996); Kacar, (2009); Hazelton ve Murphy, (2016)'ya göre kireçli ve çok fazla kireçli sınıfları arasında bulunan toprakların organik madde içerikleri genellikle düşük seviyelerde belirlenmiştir. Organik madde içeriklerindeki pozitif çarpıklık katsayısı sağa çarpıklığın bir göstergesidir. Bu durum düşük organik madde içerikli örnek sayısının fazla olduğunun bir sonucudur. Göller bölgesi topraklarının \% 65'inin organik madde içerikleri az (\% 0 - 2) sınıfında yer almaktadır (Güçdemir, 2006). Söz konusu bu düşüklük tipik olarak kurak ve yarı kurak bölgelerde vejetasyonun zayıflığı ve işlemeyle birlikte oksitlenmenin artmasıyla ilişkilendirilebilir. Toprakların pH özelliği sola çarpık (sağa yığılma) olup diğer özellikler sağa çarpık (sola yı̆̆ılıma) dağılım göstermiş̧tir. Kil, HA ve EC normale göre daha basık (-) dağılım eğrisi oluştururken, $\mathrm{CaCO}_{3}$ dışında diğer özellikler normale göre daha dik (+) bir dağılım sergilemiştir. Atabey ovası çevresinde kireç taşlarından oluşmuş yamaçların bulunması (Akgül ve ark., 2001) çalışma alanının kireç içeriklerinin yüksekliğinin bir göstergesidir. Toprakların hacim ağıllı̆̆ 1 içerikleri $1.07-1.72 \mathrm{~g} . \mathrm{cm}^{-3}$ ' dir. TK, SN ve YSİ içerikleri sırasıyla \% 23.30-47.57, 12.09-29.50, 9.98-21.87 aralıklarında değişim göstermiştir. Rawls ve ark. (1982), orta-ince tekstür grubu toprakların, TK ve SN seviyelerini \% 12.6-46.6, ve \% 3.1-33.6 aralıklarında belirlemiştir. Toprağın TK ve SN içerikleri; tekstür, organik madde ve strüktüre bağlı olarak değişim göstermekte olup tane büyüklügü̈nün küçülmesi, organik madde içeriğinin artması ve strüktürün iyileşmesi ile söz konusu nem sabitelerinde tutulan nem miktarı artmaktadır (Karahan ve ark., 2014). Ortalama nem içerikleri karşılaştırıldığında TK (\% 34.91) ile SN (\% 20.53) arasında yaklaşık 1.7'lik kat oranı bulunmaktadır. Diallo ve Mariko (2013), söz konusu bu oranı 1.6 olarak belirlemiştir. Toprak özelliklerindeki değişkenliği belirlemede kullanılan varyasyon katsayısı incelendiğinde $\mathrm{pH}, \mathrm{HA}, \mathrm{TK}, \mathrm{SN}$ ve YSI 'düşük', $\mathrm{CaCO}_{3}, \mathrm{EC}$ ve kil, silt 'orta' diğer özellikler ise 'yüksek' değişkenlik göstermiştir (Wilding 1985). Stabil olan toprak özellikleri diğer dinamik özelliklere göre daha dar bir aralıkta değişmektedir (Wilding ve ark. 1994). Değişim aralığının dar olması varyasyon katsayısının düşük olmasının bir sebebidir. 
JOTAF/ Journal of Tekirdag Agricultural Faculty, 2020, 17(3)

\subsection{Toprak Su Içeriğinin Belirlenmesinde Uygun Modellerin Belirlenmesi ve Dă̆ılım Haritalarının Oluşturulması}

Toprakların TK, SN, YSİ ile kil oranlarına ait dağılımlar Kolmogorov-Smirnov testi ile kontrol edilmiş yarayışlı su içerikleri hariç normal dağılım gösterdikleri belirlenmiştir. Dağılım haritalarının oluşturulma aşamasında kullanılan özelliklerin dağılım durumları Kolmogorov-Smirnov testi ile test edildikten sonra normal olmayan verilere hangi dönüşümlerin yapılacağı çarpıklık katsayılarına bakılarak değerlendirilmiştir. Tarla kapasitesi ve SN değişkenlerinin basıklık değerinin pozitif olması normalden daha dik bir dağılıma ve çarpıklık katsayılarının da 0'dan büyük olması nedeniyle + yöne eğimli ve sağa çarpık bir dağılımın göstergesidir. Özellikle YSİ'de çarpıklık değeri 0.5 'den büyük olması nedeniyle logaritmik dönüşüm kullanılmıştır. Ayrıca kil, TK, SN ve YSİ için oluşturulan yarıvariogram modellerin uygunlunun değerlendirilmesinde RMSE, MAE ve $\mathrm{R}^{2}$ değerleri hesaplanarak RMSE ve MAE değerlerinde en düşük, korelasyon katsayısı değerinde ise en yüksek değer dikkate alınarak kontrol edilmiştir. Degado ve ark., (2010)' a göre 0.90 ve üzeri korelasyonun çok iyi olduğunu, 0.90 0.80 arasında yüksek 0.80 - 0.70 arasında iyi, 0.70 - 0.60 arasında orta, $0.60-0.50$ arasında düşük, 0.50 den düşük ise çok düşük korelasyon olduğunu belirtmiştir. Çalışmada korelasyon katsayısı değerleri 0.5 den düşük çıkması nedeniyle $\mathrm{R}^{2}$ değerlendirmeye alınmamıştır. Ayrıca yüksek $\mathrm{R}^{2}$ her zaman gözlemlerin iyi tahminde bulunacağına anlamına gelmemektedir (Gujarati, 2003). Modelin değişim yönüyle tahmin edicilerinin aynı olması gerekmektedir. Farklı olması durumunda $\mathrm{R}^{2}$ 'ye göre geçerliliği düşük olan bir model RMSE ve MAE'ye göre yüksek doğruluk gösterebilmektedir. Bu nedenle çalışmada, birçok çalışmada da yaygın olarak kullanılan RMSE ve MAE değerleri kullanılmıştır (Arslan, 2014; Mihalikova ve ark. 2015; Tunçay ve ark. 2018).

Enterpolasyon modeller kullanılarak herhangi bir toprak özelliğinin mekânsal değişim deseninin belirlenmesi, incelenen toprak özelliğinin çalışma sahası içerisinde herhangi bir noktasındaki değerini, en az hata ile tahmin etmeye imkân sağlar. Böylece, toprak özelliklerinin enterpolasyon analizi sonucu elde edilen değişim haritaları, inceleme alanı için arazi yönetimi ile ilgili en uygun planlama ve yönetim kararlarının alınması ve uygulanmasına olanak verir (Öztaş, 1996; Özyazıcı ve ark., 2015; Gülser ve ark., 2016; Çelik ve Dengiz, 2017). Ele alınan toprak parametrelerinin dağılım haritalarını oluşturmak amacıyla 10 adet enterpolasyon modellerine ait eğitim ve test verilere ait RMSE ve MAE değerleri elde edilmiş ve Tablo 2'de verilmiştir. Hata kareler ortalaması karakökü değerleri tüm modellerde genellikle MAE değerlerinde biraz yüksek olarak belirlenmiştir. Aralarındaki farkın artmış olması veri seti içerisindeki değişimin daha yükselmesine neden olur.

Tablo 2. Ĕgitim ve test verilerinin OK, IDW, CoK ve RBF ait MAE ve RMSE dĕgerleri

Table 2. MAE and RMSE values of training and test data belonging to $O K, I D W, C o K$ and RBF.

\begin{tabular}{|c|c|c|c|c|c|c|c|c|c|c|c|c|}
\hline \multirow{2}{*}{$\begin{array}{c}\text { Toprak } \\
\text { Su }\end{array}$} & \multirow{2}{*}{$\begin{array}{l}\text { Veri } \\
\text { Seti }\end{array}$} & \multirow{2}{*}{$\begin{array}{c}\text { İstatistiksel } \\
\text { Özellik }\end{array}$} & \multicolumn{3}{|c|}{ OK } & \multicolumn{3}{|c|}{ IDW } & \multirow{2}{*}{$\begin{array}{c}\text { CoK } \\
\mathrm{K}\end{array}$} & \multicolumn{3}{|c|}{ RBF } \\
\hline & & & $\mathbf{K}$ & $\ddot{\mathbf{U}}$ & G & 1 & 2 & 3 & & CRS & STP & TPS \\
\hline \multirow{4}{*}{ TK } & Eğitim & MAE & 3.277 & 3.284 & 3.267 & 3.283 & 3.413 & 3.561 & 3.255 & 3.722 & 3.569 & 4.723 \\
\hline & Verisi & RMSE & 4.299 & 4.308 & 4.289 & 4.335 & 4.472 & 4.643 & 4.281 & 4.824 & 4.656 & 6.190 \\
\hline & Test & MAE & 3.544 & 3.533 & 3.531 & 3.505 & 3.592 & 3.679 & 3.557 & 3.698 & 3.621 & 3.906 \\
\hline & Verisi & RMSE & 4.235 & 4.235 & 4.234 & 4.267 & 4.441 & 4.643 & 4.240 & 4.674 & 4.511 & 5.075 \\
\hline \multirow{4}{*}{$\mathrm{SN}$} & Eğitim & MAE & 2.467 & 2.476 & 2.457 & 2.488 & 2.552 & 2.624 & 2.450 & 2.722 & 2.631 & 3.431 \\
\hline & Verisi & RMSE & 3.209 & 3.219 & 3.201 & 3.255 & 3.313 & 3.393 & 3.187 & 3.495 & 3.406 & 4.364 \\
\hline & Test & MAE & 2.865 & 2.886 & 2.843 & 2.950 & 3.053 & 3.131 & 2.842 & 3.180 & 3.109 & 3.331 \\
\hline & Verisi & RMSE & 3.397 & 3.420 & 3.374 & 3.495 & 3.640 & 3.776 & 3.373 & 3.839 & 3.719 & 4.129 \\
\hline \multirow{4}{*}{ YSİ } & Eğitim & MAE & 1.823 & 1.767 & 1.772 & 1.753 & 1.878 & 1.937 & 1.787 & 1.989 & 1.927 & 2.555 \\
\hline & Verisi & RMSE & 2.402 & 2.340 & 2.350 & 2.316 & 2.408 & 2.483 & 2.320 & 2.562 & 2.483 & 3.199 \\
\hline & Test & MAE & 1.199 & 1.179 & 1.801 & 1.115 & 1.169 & 1.257 & 1.199 & 1.272 & 1.204 & 1.423 \\
\hline & Verisi & RMSE & 1.549 & 1.503 & 1.528 & 1.421 & 1.468 & 1.555 & 1.549 & 1.587 & 1.506 & 1.870 \\
\hline
\end{tabular}

TK: Tarla kapasitesi, SN: Solma noktası, YSİ: Yarayışlı su içeriği, MAE:Ortalama mutlak hata (\%), RMSE: Hata kareler ortalaması karekökü(\%), K: Küresel, Ü: Üssel, G: Gaussian, CoK: CoKriging

Modeller arasında karşılaştırmanın yapılmasında Tablo 2’ den de görüleceği üzere, TK için modeller arasında gerek eğitim verilerinde gerekse de test verilerinde en düşük RMSE ve MAE değerlerini OK'ya ait Gaussan model 

vermiş iken, SN'de CoK'a ait küresel model belirlenmiştir. Topraklarda YSİ için en uygun dağılım modeline ait en düşük RMSE ve MAE değeri gerek eğitim verisinde gerekse de test verilerinde IDW modele ait 1 . kuvvette belirlenmiştir.

Tarla kapasitesinin konumsal dağılım haritası oluşturulmasında OK'un üç variyogram modelleri içerisinde Gaussan model eğitim verisinde MAE değeri \% 3.267, test verisinde ise \% 3.531 olarak belirlenirken RMSE değeri eğitim verisinde \% 4.289 ve test verisinde \% 4.234 olarak yakın değerler sergilemiştir (Tablo 2). Buna karşın en yüksek değerler ise RBF ait alt modellerde belirlenmiştir. Beş alt modele sahip olan RBF içerisinde araştırmalarda en fazla kullanılan CRS, STP ve TPS modeller mevcut çalışmada ele alınmıştır (Teartisup ve ark, 2007; Arslan, 2014). Ele alınan variogram modelllerden TPS'de, eğitim ve test verilerinde MAE değerleri sırasıyla \% 4.723 ve 3.906, RMSE değerlerinde ise \% 6.190 ve 5.075 olarak belirlenmiştir (Tablo 2). Dağılım haritalarının oluşturulması ele alınan alan içerisinde problem olan yer veya yerlerin belirlenmesi ile, alan içerisindeki dikkate alınan herhangi bir özelliğin eğilim dağılımlarını göstermesi açısından önemli kanıtları ortaya koymaktadır. Bu nedenle her bir farklı ekolojik alan için alana ait güvenilir ve doğru konumsal dağılım haritaların üretilmesinde çoklu model karşılaştırmaların yapılması ve en uygun modelin belirlenmesi en doğru yaklaşım olarak görülmektedir. Mevcut çalışma alanının TK dağılım haritası ise OK'ın Gaussan modeline göre oluşturulmuş ve Şekil 3' de verilmiştir. Çalışma alanı içerisinde TK büyük oranda \%33.16 ile 36.04 arasında değişmekte olup, güney doğu kesimlere doğru bu oran bir miktar azalarak \%31.18'e kadar azalmaktadır. Kriging yönteminde sadece birincil değişkene ait veriler kullanılarak kestirim yapılmaktadır. Ancak CoK (eş kestirim) yönteminde ikincil veriler de kullanılarak birincil verilerin olmadığı konumlarda ikincil veriler kullanılarak kestirim kalitesi arttırmak mümkündür. Fakat bu her zaman en iyi modeli belirleyecek anlamına da gelmemektedir.

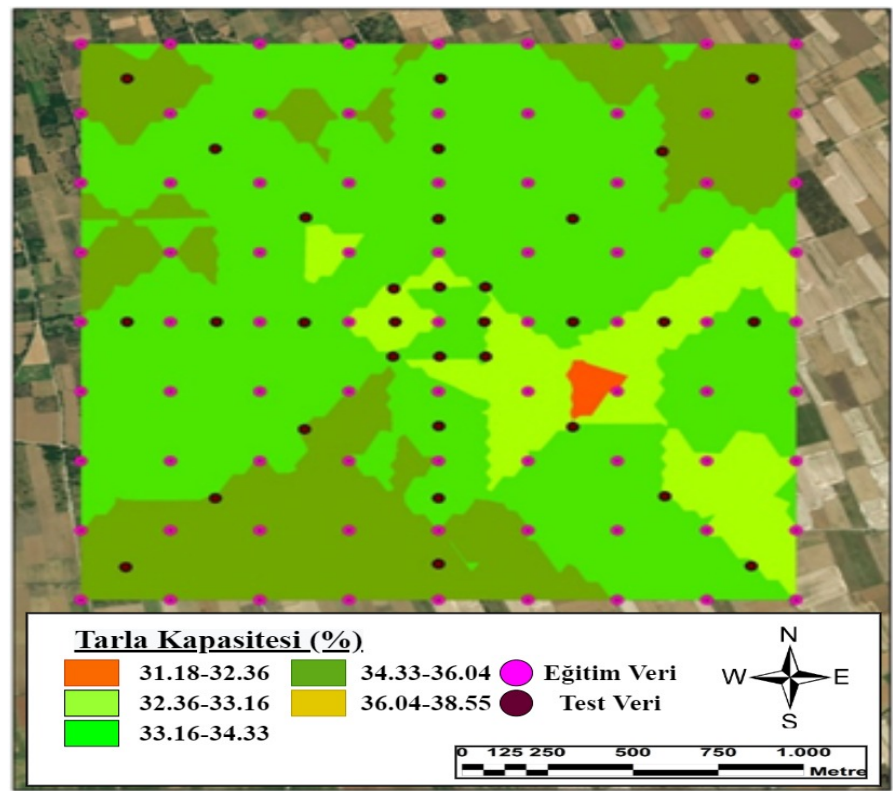

Figure 3. Field capacity distribution map of the study area

\section{Şekil 3. Çalışma alanına ait tarla kapasitesi dă̆ılım haritası}

Toprakların SN'ye ait konumsal dağılım haritası oluşturulmasında en düşük RMSE ve MAE değeri diğer modeller ile karşılaştırıldığında CoK'a ait semivariogram olarak küresel modelde belirlenmiştir. Eğitim ve test verilerinde MAE değerleri surasıyla \% 2.450 ve 2.842, RMSE değerlerinde ise \% 3.187 ve 3.373 olarak bulunmuştur (Tablo 2).Mihalikova ve ark., (2016) Orta ve Doğu Karadeniz Bölgesinde tarım arazilerine ait 3400 toprak örneği ile $k$-Nearest pedotransfer fonksiyon kullanılarak tahminleme yaptıkları çalışmada, toprakların SN dağılım haritası oluşturulmasında sekiz model kullanılmış ve RMSE değerleri dikkate alınarak simple kriginge ait Gaussan model ile en yüksek doğruluklu dağılım haritası üretilmiştir. Mevcut çalışmada, SN değerleri kil yardımcı değişkeni ile CoK yöntemi aracılığıyla tahmin edilmiş ve dağılım haritası oluşturulmuştur (Şekil 4). Solma noktası özellikle kil miktarına da bağlı olarak çalışma alanın güney kesimlerinde artış gösterirken orta kesimlerde bu oran azalma eğilimi sergilemiştir. 


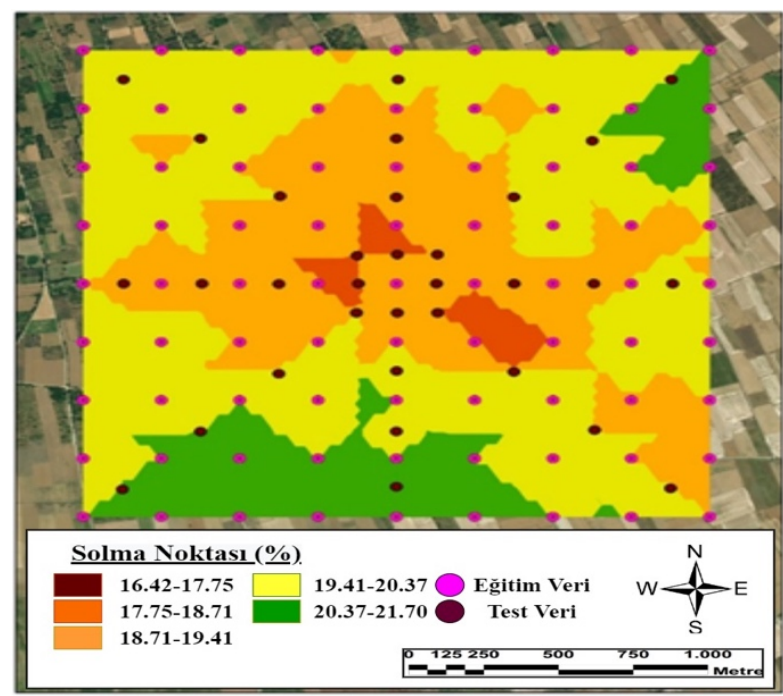

Figure 4. Wilting point distribution map of the study area

\section{Şekil 4. Çalışma alanına ait solma noktası dağılım haritası}

Toprakların YSİ değerlerine ait konumsal dağılım haritası oluşturulmasında en düşük RMSE ve MAE değerleri, diğer modeller ile karşılaştırıldığında IDW-1'de elde edilmiştir. Eğitim ve test verilerinde MAE değerleri sırasıyla \% 1.753 ve 1.115 , RMSE değerlerinde ise \% 2.316 ve 1.421 olarak belirlenmiştir. Buna karşın MAE ve RMSE değerleri OK'a ait Gaussan modeli test verileri için en yüksek model olarak gözükürken, eğitim verileri için RBF'e ait TPS modeli belirlenmiştir. Çalışma alanı topraklarının YSİ'ye ait dağılım haritası ise IDW-1 modeline göre oluşturulmuş ve Şekil 5' de verilmiştir. Yarayışlı su içeriği özellikle çalışma alanının orta ve kuzey, kuzey batı kesimlerinde artış, kuzey doğu ve güney doğu kesimlerde azalma eğilimi göstermiştir.

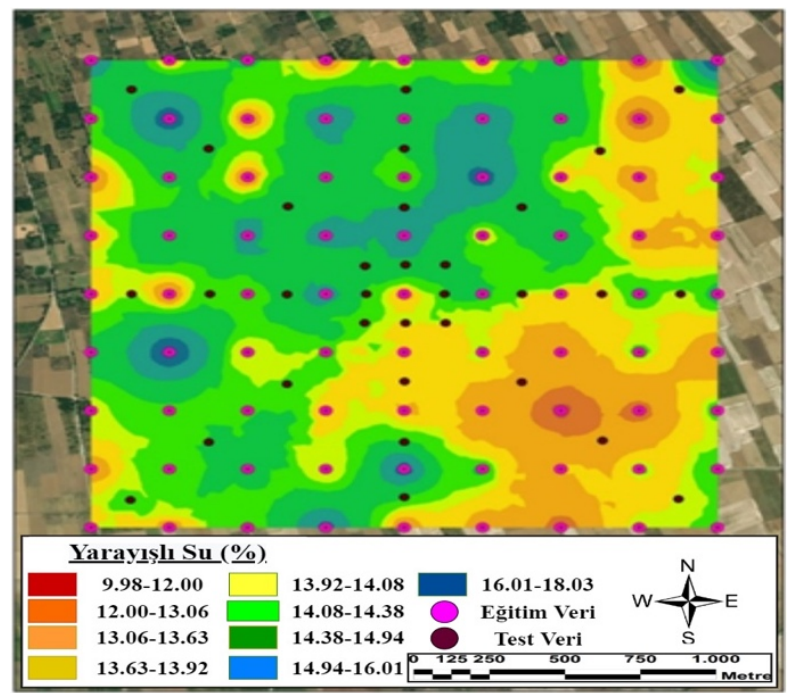

Figure 5. Available water distribution map of the study area

\section{Şekil 5. Çalışma alanına ait yarayışlı su dağılım haritası}




\section{Sonuç}

Çalışma Isparta ilinin yoğun tarım uygulamalarının yapıldığı Atabey Ovasında gerçekleştirilmiş olup çalışmada; $200 \mathrm{~m}$ aralıkla oluşturulan grid sisteminden eğitim verisi olarak 81 toprak örneği ile test verileri oluşturmak amacıyla da 32 noktadan toplamda 113 toprak örneği ile toprakların su içeriklerine yönelik olarak TK, SN ve YSİ'nin farklı enterpolasyon modeller kullanarak konumsal dağılım haritaları elde edilmiştir. Kullanılan enterplasyon modellerinden iki tanesi deterministik (IDW ve RBF), diğer iki tanesi ise (OK ve CoK) stokastik modellerdir. Elde edilen analiz sonuçları kullanılarak önce her bir değişken için tanımlayıcı istatistikler yapılmış, daha sonra uzaysal değişkenliği belirlemek amacıyla uygun teorik variogramlar belirlenmiştir. Seçilen variogram modellerinin, alanın uzaysal yapısının doğru olarak yansıtıp yansıtmadığı çapraz doğrulama analizleri ile kontrol edilmiştir. Modellerin karş1laştırarak en uygun modellerin belirlenmesinde, MAE ve RMSE değerleri dikkate alınmış ve test veriler ile oldukça yakın değerler elde edilmiştir. Alanda dağılım gösteren toprakların TK'ya ait uzaysal dağılımlarının elde edilmesinde en uygun model OK'nın Gaussan modeli belirlenirken, SN'nin uzaysal dağılımında stokastik yaklaşım olan CoK en uygun dağılımı vermiştir. Toprakların YSİ dağılımında ise IDW-1 en uygun model olarak belirlenmiştir.

Sonuç olarak gerçekleştirilen çalışmada, $200 \mathrm{~m}$ mesafelerde oluşturulan grid yöntemi için veri setinin \% 70'inin eğitim ve \% 30'unun test amaçlı kullanılmasıyla farklı jeoistatistiksel enterpolasyon yöntemleri kullanılarak toprak nem sabitelerinin dağılımları yaklaşık \% 1-4 arasında ortalama hata ile tahmin edilebilmiştir. Strüktürel yapı ve gözenek boyutlarından oldukça etkilenen TK ve daha çok tekstür ile ilişkili olan SN nem sabitelerinin kısa mesafelerdeki değişim ihtimalleri göz önüne alındığında; örnekleme sayısının arttırılması, eğitim ve test veri setlerinin oranlarının değiştirilmesi, daha kısa mesafelerde geniş alanların değerlendirilmesi ile gelecekte benzer özellikte yarı kurak ekolojik özelliklere sahip alanlarda yapılacak çalışmalarda tahmin gücünün artabileceği düşünülmektedir. 


\section{Kaynakça}

Ahmadi, M., Dezfouli, A.B.Z. (2011). A geo-statistical approach to the change procedure study of under-ground water table in a GIS framework, case study: Razan-Ghahavand Plain, Hamedan Province, Iran. Journal of Academic and Applied Studies, 2(11): 56-69.

Akgül, M., Başayiğit, L., Uçar, Y. (2002). Atabey Ovası topraklarının genel özellikleri ve sınıflandırılması. Süleyman Demirel Üniversitesi Fen Bilimleri Enstitüsü Dergisi, 6(1): 1-13.

Akgül, M., Başayiğit, L., Uçar, Y., Müjdeci, M. (2001). Atabey Ovası Toprakları. Süleyman Demirel Üniversitesi Ziraat Fakültesi Yayın No: $15,71 \mathrm{~s}$, Isparta.

Arslan, H. (2014). Estimation of spatial distrubition of groundwater level and risky areas of seawater intrusion on the coastal region in Çarşamba Plain, Turkey, using different interpolation methods. Environmental Monitoring and Assessment, 186(8): 5123-5134.

Arslan, H. (2012). Spatial and temporal mapping of groundwater salinity using ordinary kriging and indicator kriging: The case of Bafra Plain, Turkey. Agricultural Water Management, 113: 57-63.

Aşkın, T., Türkmen, F., Tarakçığlu, C. (2016). Ordu ili merkez ilçe topraklarında erozyon riskinin jeoistatistiksel tekniklerle değerlendirilmesi. Toprak Bilimi ve Bitki Besleme Dergisi, 4(2): 69-75.

Aydın, A. Dengiz, O. (2019) Yarı-Humid ekolojik koşullar altında oluşmuş toprakların bazı fiziko-kimyasal özelliklerinin belirlenmesi, haritalanması ve sinıflandırması. Toprak Su Dergisi, 8(2): 68-80.

Bayat, B. B., Zahraie, B., Taghavi, F., Nasseri, M. (2013). Evaluation of spatial and spatiotemporal estimation methods in simulation of precipitation variability patterns. Theoretical and Applied Climatology, 113(3-4): 429-444.

Bouyoucos G.J. (1962): Hydrometer method improved for making particle size analyses of soils. Agron. J., 54: 464-465.

Burrough, P. A., McDonnell, R. A. (1998). Principles of geographical information systems. New York: Oxford University Press.

Burt, R. (Ed.). (2014). Soil survey field and laboratory methods manual. United States Department of Agriculture, Natural Resources Conservation Service, National Soil Survey Center, Natural Resources Conservation Service, Kellog Soil Survey Laboratory.

Celilov, C., Dengiz, O. (2019). Erozyon duyarlılık parametrelerinin farklı enterpolasyon yöntemleriyle konumsal dağılımlarının belirlenmesi: Türkiye, Ilgaz milli park toprakları. Türkiye Tarımsal Araştırmalar Dergisi, 6(3).

Cemek, B., Güler, M., Kılıc, K., Demir, Y., Arslan, H. (2007). Assessment of spatial variability in some soil properties as related to soil salinity and alkalinity in Bafra plain in northernTurkey. Environmental Monitoring and Assessment, 124: $223-234$.

Corine (2018). Corine land use land cover map of Turkey. https://corinecbs.tarimorman.gov.tr/(12.-1.2020).

Çelik, P., Dengiz, O. (2017). Akselendi Ovası tarım topraklarının temel toprak özellikleri ve bitki besin elementi durumlarının belirlenmesi ve dağılım haritalarının oluşturulması. Türkiye Tarımsal Araştırmalar Dergisi, 5(1): 9-18.

Degado, C., Pacheco, J., Cabrera, A., Batllori, E., Orellana, R., Bautista, F. (2010) . Quality of groundwater for irrigation in tropical karst environment: The case of Yucatan, Mexico. Agricultural Water Management, 97: 1423-1433.

Dengiz, O., Saygın. F., İmamoğlu, A. (2019). Spatial variability of soil organic carbon density under different land covers and soil types in a sub-humid terrestrial ecosystem. Eurasian Journal of Soil Science, 8(1): 35-43.

Devlet Su işleri (DSI) (2019). Erişim Tarihi:23.11.2019. http://www.dsi.gov.tr/.

Diallo, D., Mariko, A. (2013). Field capacity (FC) and permanent wilty point (PWP) of clay soils developed on quaternary alluvium in Niger River Loop (Mali). International Journal of Engineering Science, 3: 1085-1089.

Doran, J.W., Jones, A.J. (1996) Methods for Assessing Soil Quality, Soil Science Society of America Special Publication 49, SSSA, Madison, WI,

Falamaki, A. (2011). Artificial neural network application for predicting soil distribution coefficient of nickel. Journal of Environmental Radioactivity, 115: 6-12.

Grewal , K.S., Buchan, G.D., Tonkin, P.J. (1990). Estimation of field capacity and wilting point of some new zealand soils from their saturation percentages. New Zealand Journal of Crop and Horticultural Science, 18(4): 241-246.

Gujarati, D. (2003). Basic Econometrics. 4th ed. New York: McGraw Hill, pp. 638-640.

Güçdemir, İ.H. (2006). Türkiye Gübre ve Gübreleme Rehberi. Güncelleştirilmiş ve Genişletilmiş 5. baskı. Tarımsal Araştırmalar Genel Müdürlüğü, Toprak ve Gübre Araştırma Enstitüsü Müdürlüğü Yayınları, Genel Yayın No: 231, Ankara.

Gülser, C., Ekberli, İ., Candemir, F., Demir, Z. (2016). Spatial variability of soil physical properties in a cultivated field. Eurasian Journal of Soil Science, 5(3): 192-200.

Hazelton, P., Murphy, B. (2016). Interpreting soil test results: What do all the numbers mean?. CSIRO publishing.

Hong, S. Y., Minasny, B., Han, K. H., Kim, Y., Lee, K. (2013). Predicting and mapping soil available water capacity in Korea. PeerJ, 1, e71. 
Alaboz \& Demir \& Dengiz Determination of spatial distribution of soil moisture constant using different interpolation model case study, Isparta Atabey plain Intergovernmental Panel on Climate Change (IPCC), (2014). Fifth Assessment Report (AR5). https://www.ipcc.ch/report/ar5/syr/. (Erişim tarihi:30.01.2020).

Kacar, B. (2009). Toprak Analizleri. Nobel Yayın Dağıtım, 467s, Ankara.

Karahan, G., Erşahin, S., Öztürk, H.S. (2014). Toprak koşullarına bağlı olarak tarla kapasitesi dinamiği. Gaziosmanpaşa Üniversitesi Ziraat Fakültesi Dergisi, 30(1): 1-9.

Keshavarz1, A., Sarmadian, A. (2012). Mapping of spatial distribution of soil salinity and alkalinity in a semi-arid region. Annals of Warsaw University of Life Sciences, Land Reclamation, 44(1): 3-14.

Mbah, C.N. (2012). Determining the field capacity, wilting point and available water capacity of some Southeast Nigerian soils using soil saturation from capillary rise. Nigerian Journal of Biotechnology, 24: 41-47.

Meteoroloji Genel Müdürlügü (MGM), (2018). Erişim tarihi: 20.01.2018. http://www. mgm.gov.tr/veridegerlendirme/yillik-toplam-yagis verileri .aspx \#sfU.

Miháliková, M, Özyazıcı, M.A., Dengiz, O. (2016). Mapping soil water retention on agricultural lands in central and eastern parts of the Black Sea Region in Turkey. Journal of Irrigation and Drainage Engineering, 142(12): 05016008-1.

Mihalikova, M., Başkan, O., Dengiz, O. (2015). Capability of different interpolation models and pedotransfer functions to estimate soil hydraulic properties in Büyükçay Watershed. Environmental Earth Sciences, 74: 2425-2437.

Öztaş, T. (1996). Eğimli bir arazide erozyonla kaybolan toprak derinliğindeki değişimin Kriging analizi ile belirlenmesi. Tarım-Çevre İlişkileri Sempozyumu, "Doğal Kaynakların Sürdürülebilir Kullanımı”, 13- 15 Mayıs, Mersin, s. 327-335.

Özyazıcı, M. A., Dengiz, O., Aydoğan, M., Bayraklı, B., Kesim, E., Urla, Ö., ... Ünal, E. (2016). Orta ve Doğu Karadeniz Bölgesi tarım topraklarının temel verimlilik düzeyleri ve alansal dağılımları. Anadolu Tarım Bilimleri Dergisi, 31(1); 136-148.

Özyazıcı, M.A., Dengiz, O., Aydoğan, M., Bayraklı, B., Kesim, E., Urla, Ö., Yıldız, H., Ünal, E. (2015). Orta ve Doğu Karadeniz Bölgesi tarım topraklarının bazı makro ve mikro bitki besin maddesi konsantrasyonları ve ters mesafe ağırlık yöntemi (IDW) ile haritalanması. Artvin Çoruh Üniversitesi Orman Fakültesi Dergisi, 16(2): 187-202.

Pirmoradian, N., Rezaei, M., Davatgar, N., Tajdari, K., Abolpour, B. (2010). Comparing of interpolation methods in rice cultivation vulnerability mapping due to groundwater quality in Guilan, north of Iran. International Conference on Environmental Engineering and Applications (ICEEA) 147-150, Singapore.

Rawls, W.J., Brakensiek, D.L., Saxton, K.E. (1982). Estimation of soil water properties. Transactions ASAE, 25(5): 1316-1328.

Sağlam, M., Dengiz, O., Selvi, K. Ç., Gürsoy, E. F., Atasoy, Ç. (2014). Farklı toprak işleme yöntemlerinin killi toprağın bazı fiziksel özellikleri üzerine etkilerinin jeoistatistiksel yöntemle değerlendirilmesi. Toprak Su Dergisi, 3(1).

Silva, B. M., Silva, É. A. D., Oliveira, G. C. D., Ferreira, M. M., Serafim, M. E. (2014). Plant-available soil water capacity: estimation methods and implications. Revista brasileira de ciencia do solo, 38(2): 464-475.

Soil Survey Staff, (1992). Soil survey manuel. United States Department of Agronomy, Handbook No: 18, Washington, USA.

Teartisup, P., Kerdsueb, P., Wattaya, P. (2007). Field scale mapping of soil salinity on spatial interpolation techniques, case study: Khorat Basin, Nakhon Ratchasima Province, Thailand. Environmental Informatics Archives, 5: 524-547.

Tunçay, T., Başkan, O., Bayramin, İ., Dengiz, O., Kılıç, Ş. (2018). Geostatistical approach as a tool for estimation of field capacity and permanent wilting point in semiarid terrestrial ecosystem. Archives of Agronomy and Soil Science, 64 (9): 1240-1253.

Tutmez, B., Hatipoğlu, Z. (2010). Comparing two data driven interpolation methods for modeling nitrate distribution in aquifer. Ecological Informatics, 5: 311-315.

U.S, Salinity Laboratory Staff. (1954). Diagnosis and Improvement of Salina and Alkali Soils. Agricultural Handbook 60, U.S.D.A.

Van Wambeke, A. R. (2000). The Newhall Simulation Model for estimating soil moisture and temperature regimes. Department of Crop and Soil Sciences. Cornell University, Ithaca, NY. USA.

Wilding, L.P. (1985). Spatial Variability: Its Documentation, Accommodation and Implication to Soil Surveys, 166-194p. In D.R. Nielsen and J. Bouma (eds.). Soil Spatial Variability: Pudoc, Wageningen, Netherlands.

Wilding, L.P., Bouma, J., Goss, D.W. (1994). Impact of Spatial Variability on Interpretative Modelling. In: Quantitative Modelling of Soil Forming Processes R.B. Bryant ve Arnold R.W. (Ed.) SSSA Special Publication Number 39, SSSA,Inc. Madison Wisconsin,USA

Xie,Y., Chen, T., Lei,M., Yang, J. (2011). Spatial distribution of soil heavy metal pollution estimated by different interpolation methods: accuracy and uncertainty analysis. Chemosphere: $82,468-476$.

Yıldız, Y. (2011). Kazova Topraklarının Mikro Element İçeriklerinin Mesafeye Bağlı Değişiminin Analizi ve Bazı Toprak Özellikleri Arasındaki İlişkiler (Basılmamış Yüksek Lisans Tezi). Gaziosmanpaşa Üniversitesi, Toprak Anabilim Dalı Tokat.

Zhou, Z., Zhang, G., Yan, M., Wang, J. (2012). Spatial variability of the shallow groundwater level and its chemistry characteristics in the low plain around the Bohai Sea, North China. Environmental Monitoring and Assessment, 18(6): 3697-3710. 